Journal of Economics and Policy
http://journal.unnes.ac.id/nju/index.php/jejak

\title{
STRATEGI PENGEMBANGAN INDUSTRI KECIL CARICA
}

\author{
Yunus Gunawan ${ }^{1}$, Adi Permadi ${ }^{2 \bowtie}$ \\ ${ }^{1)}$ Universitas Diponegoro Semarang \\ ${ }^{2)}$ Universitas Negeri Semarang, Indonesia \\ Permalink/DOI: http://dx.doi.org/10.15294/jejak.v8i1.3853 \\ Received : 15 Desember 2014; Accepted: 6 Januari 2015; Published: March 2015
}

\begin{abstract}
The purpose of this study to find out the profiles of carica industries in Wonosobo regency and to determine what is the development strategy can be used. The variables in this research belongs to human resources, capital, technology, and marketing. Data analysis method used is descriptive analysis method and SWOT analysis. Based on the results of this study showed that small industrial profiles carica in Wonosobo regency in 2014 there were 15 business units. There are several priority development strategies did, those are SO strategy to improve the quality of human resources to improve product quality of carica, utilizing the labor of the surrounding area to increase carica industry, and optimize strategic industrial location. WO strategy to prepare the inventory in the form of stock products carica, carica optimize product to meet consumer demand, and optimize the training of relevant agencies. ST strategies to improve the quality and characteristics of products carica, requires the role of government in terms of anticipating landslides in Dieng, and carica product innovation to improve consumer tastes. WT strategy to improve the managerial capacity of employers, raise the price of products carica, and in the dry season production carica replaced with other processed food products act. Based on the research results can be concluded, the strategy adopted in this condition is to support an aggressive policy.
\end{abstract}

Keywords: Strategy Development, Small Industries, Profile, Wonosobo

\begin{abstract}
Abstrak
Tujuan penelitian ini untuk mengetahui bagaimana profil industri kecil carica di Kabupaten Wonosobo serta untuk mengetahui strategi pengembangan apa yang bisa digunakan. Variabel yang diteliti adalah profil industri yang meliputi sumber daya manusia, permodalan, teknologi, dan pemasaran. Metode analisis data yang digunakan adalah metode analisis deskriptif dan analisis SWOT. Berdasarkan hasil penelitian menunjukkan bahwa profil industri kecil carica di Kabupaten Wonosobo pada tahun 2014 ada 15 unit usaha. Ada beberapa prioritas strategi pengembangan yaang dilakukaan yaitu strategi SO dengan meningkatkan kualitas SDM, memanfaatkan tenaga kerja dari daerah sekitar, dan mengoptimalkan lokasi industri yang strategis. Strategi WO menyiapkan stok produk carica, mengoptimalkan produk carica, dan mengoptimalkan pelatihan dari dinas terkait. Strategi ST dengan meningkatkan kualitas ciri khas produk carica,peranan pemerintah dalam hal mengantisipasi bencana longsor di Dieng, dan melakukan inovasi produk carica. Strategi WT dengan meningkatkan kemampuan manajerial pengusaha, menaikkan harga jual produk carica, dan pada musim kemarau diganti dengan produk makanan komoditas Kabupaten Wonosobo. Berdasarkan hasil penelitian, strategi yang diterapkan dalam kondisi ini adalah mendukung kebijakan yang agresif, yaitu industri kecil carica di Kabupaten Wonosobo dapat bersaing dengan produk olahan makanan jenis lainnya dari berbagai daerah dengan cara menjaga dan meningkatkan kualitas produk carica yang dihasilkan.
\end{abstract}

Kata Kunci: Strategi Pengembangan, Industri Kecil, Profil, Wonosobo

How to Cite: Permadi, A. (2015). Strategi Pengembangan Industri Kecil Carica. JEJAK Journal of Economics and Policy, 8 (1): 45-53

(c) 2015 Semarang State University. All rights reserved

$\begin{array}{lc}\text { Corresponding author: } & \text { ISSN 1979-715X } \\ \text { Address: Kampus Unnes Sekaran, Semarang 50229 } & \\ \text { E-mail: permadiadi20@gmail.com } & \end{array}$




\section{PENDAHULUAN}

Melihat potensi industri yang sangat baik, tidak berarti dalam proses usahanya tidak menghadapi hambatan dan tantangan. Seperti yang dikatakan Anoraga (2002), bahwa usaha kecil menghadapi berbagai tantangan dan kendala seperti kualitas sumber daya manusia yang rendah; tingkat produktifitas dan kualitas produk dan jasa rendah; kurangnya teknologi dan informasi; faktor produksi; sarana; dan prasarana belum memadai; aspek pendanaan dan pelayanan jasa pembiayaan; iklim usaha belum mendukung; dan koordinasi pembinaan belum baik. Namun demikian ada peluang yang dapat dimanfaatkan oleh UKM dalam kegiatan usahanya, seperti: adanya komitmen pemerintah; ketersediaan sumber daya alam yang beranekaragam dan lain-lain.

Bustaman (2010) Juga menyatakan bahwa permasalahan akses modal yang lemah, produktivitas rendah, kemampuan pengelolaan usaha yang masih sederhana, akses untuk mendapatkan teknologi modern dan beban birokrasi turut memberikan permasalahan bagi sektor UMKM. Sektor UKM sendiri dibagi ke dalam beebrapa kategori. Berdasarkan karakteristik pemiliknya; berdasarkan organisasi pemiliknya; berdasarkan prioritas strategi; dan berdasarkan skala ekonomi (Kitching \& David, 2012).

Perkembangan sektor usaha kecil dan menengah hingga saat ini jumlahnya telah menggelembung sedemikian besar bahkan hampir menyamai jumlah mereka yang bekerja di sektor formal lainnya. Di banyak negara-negara miskin dan berkembang, kontribusi yang bisa diberikan oleh pelaku usaha kecil mencapai 30\%-60\% dari seluruh penduduk perkotaan. Sedangkan di wilayah Jawa jumlah pelaku sektor ini berkisar antara
$37 \%$ sampai $43 \%$, sementara di luar Jawa lebih banyak lagi berkisar antara 40\%-55\% (Sriyana, 2010).

Setiap daerah banyak tumbuh sentrasentra industri kecil yang menjadi andalan masing-masing. Seperti di Kabupaten Wonosobo yang mempunyai potensi alam yang tinggi mempunyai hasil bumi yang beranekaragam. Salah satunya adalah buah pepaya gunung atau carica. Bedanya jika pepaya biasa lebih dikenal tumbuhan tropis yang memerlukan banyak panas dan matahari, maka carica termasuk keluarga pepaya yang hanya bisa tumbuh di tempat tinggi basah, 1.500-3.00o di atas permukaan laut, memerlukan temperatur yang cukup dingin, dan banyak hujan.

Kondisi tersebut sangat cocok dengan iklim Dataran Tinggi Dieng di Kabupaten Wonosobo. Selain itu, buah papaya carica tak hanya dapat dimanfaatkan buahnya saja melainkan juga bagian tanaman yang lain seperti biji (Purwaningdyah, et al, 2014). Terdapat beberapa kendala yang dihadapi oleh industri kecil carica, dalam hal permodalan para pengusaha mengalami keterbatasan modal untuk pengembangan usahanya, keterbatasan bahan baku dan penggunaan teknologi untuk proses produksi.

Pembangunan ekonomi daerah adalah suatu proses dimana pemerintah daerah dan masyarakatnya mengelola sumber daya yang ada dan membentuk suatu pola kemitraan antara pemerintah daerah dengan sektor swasta untuk menciptakan suatu lapangan kerja baru dan merangsang perkembangan kegiatan ekonomi (pertumbuhan ekonomi) dalam wilayah tersebut (Lincolin, 1999). Pada umumnya pembangunan ekonomi yang dilakukan oleh negara-negara berkembang mempunyai tujaun antara lain untuk menciptakan pembangunan ekonomi yang hasilnya secara 
merata dinikmati oleh masyarakat, meningkatkan laju pertumbuhan ekonomi, meningkatkan kesempatam kerja, pemerataan pendapatan, mengurangi perbedaan kemampuan antar daerah, struktur perekonomian yang seimbang. Salah satu indikator untuk menilai keberhasilan dari pembangunan ekonomi suatu negara adalah dilihat dari kesempatan kerja yang diciptakan dari pembangunan ekonomi (Sagir, 2000).

\section{METODE PENELITIAN}

Penelitian ini menggunakan data primer. Data primer dikumpulkan langsung melalui observasi (pengamatan), dengan menggunakan kuesioner yang telah disiapkan sebelumnya. Dalam penelitian ini, sumber datanya adalah pemilik industri kecil carica di Kabupaten Wonosobo.

Adapun variabel dalam penelitian ini adalah Profil usaha industri kecil carica di Kabupaten Wonosobo mencakup; SDM (Tenaga Kerja) indikatornya: Jumlah tenaga kerja, tingkat pendidikan, dan usia tenaga kerja. Permodalan indikatornya modal awal dan sumber modal, Teknologi indikatornya: teknologi yang digunakan, Pemasaran indikatornya: daerah pemasaran dan promosi yang dilakukan dan Bahan Baku.
Analisis data dalam penelitian menggunakan metode analisis deskriptif. Di mana metode ini merupakan cara merumuskan dan menafsirkan data yang ada sehingga memberikan gambaran yang jelas mengenai profil industri kecil carica dan faktor internal dan eksternal industri kecil carica di Kabupaten Wonosobo.

Selanjutnya analisis SWOT. Fungsinya adalah identifikasi berbagai faktor secara sistematis untuk merumuskan faktor-faktor pendorong dan penghambat pertumbuhan dan perkembangan sektor industri kecil carica. Analisis ini didasarkan pada logika yang dapat memaksimalkan kekuatan (strength) dan peluang (opportunities), namun secara bersamaan dapat meminimalkan kelemahan (weakness) dan ancaman (treats).Berikut ini langkahlangkah selanjutnya setelah diperoleh analisis mengenai kekuatan, kelemahan, peluang, dan ancaman pada sektor industri kecil carica.

Identifikasi faktor-faktor internal dan eksternal ini diperoleh dengan memanfaatkan seluruh hasil analisis. Selanjutnya informasi yang diperoleh diklasifikasikan. Hal ini dilihat pada format tabel berikut ini:

Tabel 1. Analisis Faktor Internal dan Eksternal

\begin{tabular}{llll}
\hline Faktor-faktor Strategi Internal dan Eksternal & Bobot & Rating & Bobot x Rating \\
\hline Kekuatan & & & \\
Kelemahan & & \\
Peluang & & \\
Ancaman & & \\
\hline
\end{tabular}

Sumber: Freddy Rangkuti, 2006 hal 24-25.

Pemberian bobot masing-masing skala mulai 1,o (paling penting) sampai o,o (paling tidak penting), berdasarkan pengaruh tersebut. Semua bobot tersebut tidak boleh melebihi skor total 1,oo. Pemberian rating untuk masing-masing faktor-faktor dengan 
skala mulai dari empat sampai dengan satu, berdasarkan pengaruh faktor tersebut terhadap kondisi sektor industri kecil carica. Pemberian nilai rating untuk faktor kekuatan dan peluang yang bersifat positif semakin besar diberi rating 4, tetapi bila kecil diberi rating 1. Pemberian nilai rating kelemahan dan ancaman yang bersifat negatif semakin besar diberi rating 1 , tetapi bila kecil diberi rating 4 .

Langkah selanjutnya setelah diperoleh analisis mengenai kekuatan, kelemahan, peluang, dan ancaman pada sektor industri kecil carica adalah dengan matriks internalekstrenal.

Total skor faktor strategi internal

$\begin{array}{llll}\text { Kuat } & & \text { Rata-rata } & \text { Lemah } \\ 4,0 & 3,0 & 2,0 & 1,0\end{array}$

\begin{tabular}{|c|c|c|c|}
\hline $\begin{array}{l}\text { Total } \quad \text { 4,o Tinggi } \\
\text { Skor } \quad \text { 3,o Sedang }\end{array}$ & $\begin{array}{l}\text { I } \\
\text { Pertumbuhan }\end{array}$ & $\begin{array}{l}\text { II } \\
\text { Pertumbuhan }\end{array}$ & $\begin{array}{l}\text { III } \\
\text { Penciutan }\end{array}$ \\
\hline $\begin{array}{l}\text { Faktor Strategis 2,0 } \\
\text { Rendah }\end{array}$ & $\begin{array}{l}\text { IV } \\
\text { Stabilitas }\end{array}$ & $\begin{array}{l}\text { V } \\
\text { Pertumbuhan Stabilitas }\end{array}$ & $\begin{array}{l}\text { VI } \\
\text { Penciutan }\end{array}$ \\
\hline Eksternal 1,o & $\begin{array}{l}\text { VII } \\
\text { Pertumbuhan }\end{array}$ & $\begin{array}{l}\text { VIII } \\
\text { Pertumbuhan }\end{array}$ & $\begin{array}{l}\text { IX } \\
\text { Likuiditas }\end{array}$ \\
\hline
\end{tabular}

Sumber: Freddy Rangkuti (2006:151).

Gambar 1. Matriks Internal-Eksternal Keterangan:

I : Strategi konsentrasi melalui integrasi vertikal.

II : Strategi konsentrasi melalui integrasi horizontal.

III : Strategi turn around.

IV : Strategi stabilitas.

$\mathrm{V} \quad$ : Strategi konsentrasi melalui integrasi horizontal atau stabilitas (tidak ada perubahan dalam pendapatan).

VI : Strategi divestasi.

VII : Strategi diversifikasi konsentrik.

VIII : Strategi diversifikasi konglomerat.

IX : Strategi likuiditas (tidak berkembang). 
Analisis ini digunakan untuk digunakan dalam penelitian ini adalah menganalisis strategi pengembangan industri sebagai berikut. kecil carica di Kabupaten Wonosobo yang

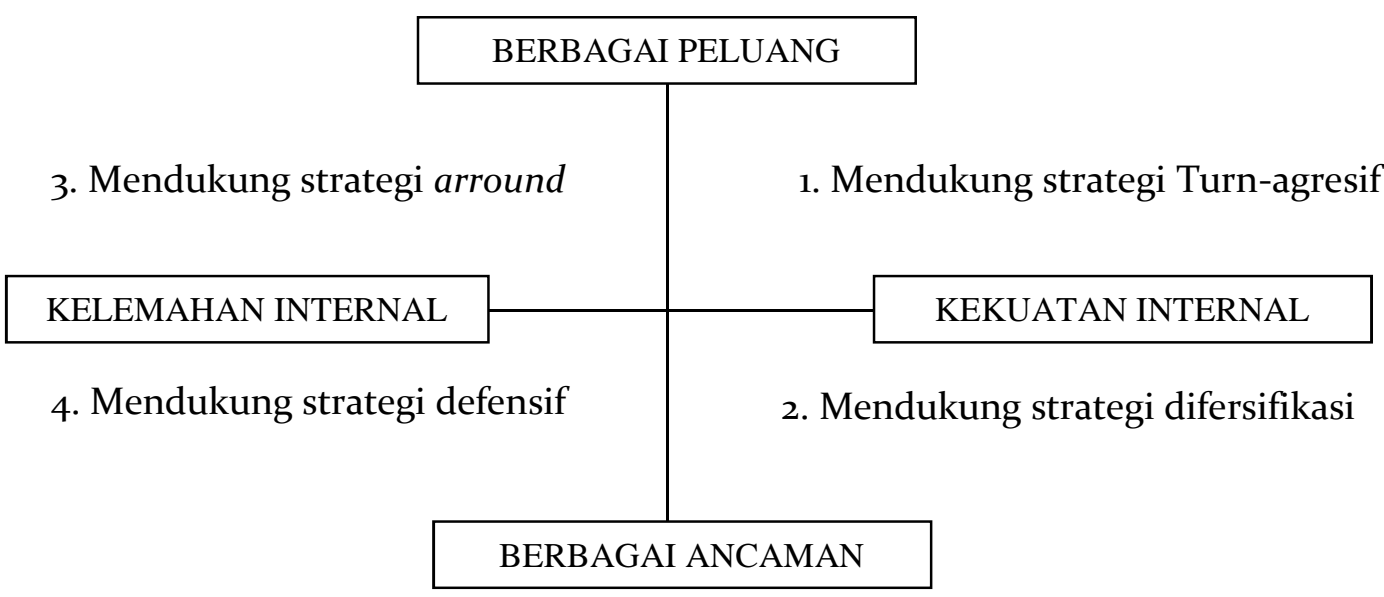

Sumber: Rangkuti (2006: 19).

Gambar 2. Matrik Analisis SWOT

Matrik ini dapat menggambarkan secara luas bagaimana peluang dan ancaman eksternal yang dihadapi industri kecil carica sehingga dapat disesuaikan denga kekuatan dan kelemahan yang dimilikinya. Matrik disesuaikan dengan kekuatan dan kelemahan yang dimilikinya. Matrik ini dapat menghasilakan empat set kemungkinan alternatif strategi

Tabel 2. Alternatif Pengembangan SWOT secara Matrik

\begin{tabular}{|c|l|l|}
\hline \multicolumn{1}{|c|}{ Faktor } & Kekuatan (S) & Kelemahan (W) \\
\hline Faktor Eksternal & $\begin{array}{l}\text { Kekuatan yang ada } \\
\text { digunakan untuk } \\
\text { mengisis peluang yang } \\
\text { tersedia(SO) }\end{array}$ & $\begin{array}{l}\text { Memanfaatkan peluang } \\
\text { yang ada dengan } \\
\text { menanggulangi } \\
\text { kelemahannya (WO) }\end{array}$ \\
\hline Ancaman (T) & $\begin{array}{l}\text { Kekuatan yang dimiliki } \\
\text { untuk mengatasi } \\
\text { ancaman yang dihadapi } \\
\text { (ST) }\end{array}$ & $\begin{array}{l}\text { Meminimalkan } \\
\text { kelemahan dan } \\
\text { menghindari ancaman } \\
\text { (WT) }\end{array}$ \\
\hline
\end{tabular}

Sumber: Freddy Rangkuti,2oo6.

HASIL DAN PEMBAHASAN

Unit usaha industri kecil carica di Kabupaten Wonosobo tersebar di tiga kecamatan, yaitu Kecamatan Kejajar, Mojotengah, dan Wonosobo. Terdapat 15 unit usaha industri kecil carica di Kabupaten 
Wonosobo, dimana jumlah terbanyak terdapat di Kecamatan Wonosobo yaitu ada 9 unit usaha.

Dari hasil penelitian diketahui bahwa penggunaan tenaga kerja pada industri kecil carica di Kabupaten Wonosobo mayoritas antara 6 - 10 orang tenaga kerja. Dilihat dari segi sumber daya manusia (tenaga kerja), hasil penelitian menunjukkan bahwa sebagian besar pengusaha industri kecil carica di Kabupaten Wonosobo berjenis kelamin laki-laki (53,33\%), berumur 30-39, 40-49, 50-59 tahun (26,67\%) dan berpendidikan tamat SLTA (53,33\%). Dengan adanya industri kecil carica di Kabupaten Wonosobo mampu menyerap tenaga kerja yang cukup banyak dari daerah sekitar industri. Tenaga kerja yang terserap pada industri kecil carica di Kabupaten Wonosobo menurut data terakhir tahun 2014 sebanyak 162 tenaga kerja.

Ditinjau dari segi permodalan, hasil penelitian menunjukkan bahwa sebagian besar sumber modal industri kecil carica di Kabupaten Wonosobo berasal dari modal sendiri atau pribadi yaitu sebanyak 12 pengusaha $(80 \%)$ dan modal awal pendirian usaha sebesar antara $\mathrm{Rp}$ 1.00o.0oo,- s/d Rp 5.000.00o,-. Keputusan pengusaha untuk menggunakan modal pribadi dikarenakan pengusaha pada industri kecil carica di Kabupaten Wonosobo memang menghindari pinjaman dari perbankan karena mempunyai resiko yang tinggi dan takut tidak bisa mengangsur pinjamannya beserta bunga tinggi yang dikenakan, ada pula yang mengaku takut pinjaman tersebut tidak bisa dikelola dengan baik sehingga akan menyebabkan kerugian. Ditinjau dari segi teknologi, hasil penelitian menunjukkan peralatan yang digunakan masih semi tradisional. Proses produksi carica di Kabupaten Wonosobo sebagian besar kegiatannya dilakukan di tempat khusus (pabrik) yang biasanya berlokasi disamping rumah pemiliki usaha.

Tabel 3. Analisis Matrik IFE Industri Kecil Carica di Kabupaten Wonosobo

\begin{tabular}{llll}
\hline \multicolumn{1}{c}{ Kekuatan } & & & \\
\hline \multicolumn{1}{c}{ Faktor-Faktor Strategi Internal } & $\begin{array}{c}\text { Bobot } \\
\text { Rata-rata }\end{array}$ & $\begin{array}{c}\text { Rating } \\
\text { Rata-rata }\end{array}$ & $\begin{array}{c}\text { Bobot x } \\
\text { Rating }\end{array}$ \\
\hline (A) Kualitas produk sesuai selera & $\mathbf{0 , 0 9 6}$ & 3,887 & $\mathbf{0 , 3 7 3}$ \\
(B) Adanya inovasi produk carica & $\mathbf{0 , 0 9 6}$ & $\mathbf{2 , 0 6 7}$ & $\mathbf{0 , 1 9 8}$ \\
(C) Ketrampilan tenaga kerja memadai & $\mathbf{0 , 0 9 1}$ & 3,733 & $\mathbf{0 , 3 4}$ \\
(D) Tenaga kerja dekat dengan lokasi usaha & $\mathbf{0 , 1 0 9}$ & 3,133 & $\mathbf{0 , 3 4 1}$ \\
(E) Lokasi industri dekat dengan pasar & $\mathbf{0 , 1 1 9}$ & $\mathbf{3 , 6 6 7}$ & $\mathbf{0 , 4 3 6}$ \\
Kelemahan & & & \\
(F) Keterbatasan bahan baku yang tersedia & $\mathbf{0 , 0 8 5}$ & $\mathbf{1 , 0 6 7}$ & $\mathbf{0 , 0 9 1}$ \\
(G) Dana investasi dan modal kerja terbatas & $\mathbf{0 , 0 8 8}$ & $\mathbf{1 , 1 3 3}$ & $\mathbf{0 , 1}$ \\
(H) Mahalnya harga teknologi modern & $\mathbf{0 , 1 1 8}$ & $\mathbf{2 , 3 3 3}$ & $\mathbf{0 , 2 7 5}$ \\
(I) Keterbatasan industri memenuhi permintaan & $\mathbf{0 , 0 8 8}$ & $\mathbf{1 , 2}$ & $\mathbf{0 , 1 0 6}$ \\
(J) Manajemen belum maksimal & $\mathbf{0 , 1 1}$ & $\mathbf{1 , 8}$ & $\mathbf{0 , 1 9 8}$ \\
& & & $\mathbf{2 , 4 5 8}$ \\
\hline
\end{tabular}

Sumber: data primer, diolah, 2014 . 
Kekuatan dan kelemahan utama bagi industri carica digambarkan pada tabel diatas. Kekuatan utama industri carica adalah variabel kekuatan yang memiliki nilai bobot $\mathrm{x}$ rating terbesar, yakni lokasi industri dekat dengan pasar. Dengan nilai bobot $\mathrm{x}$ rating 0,436 .Kelemahan utama industri carica adalah keterbatasan bahan baku yang tersedia dengan nilai bobot $\mathrm{x}$ rating terkecil yaitu 0,091.

Tabel 4. Analisis Matrik EFE Industri Kecil Carica di Kabupaten Wonosobo

\begin{tabular}{llll}
\hline \multicolumn{4}{c}{ Peluang } \\
\multicolumn{1}{c}{ Faktor-Faktor Strategi Eksternal } & \multicolumn{1}{c}{$\begin{array}{c}\text { Bobot } \\
\text { Rata-rata }\end{array}$} & $\begin{array}{c}\text { Rating } \\
\text { Rata-rata }\end{array}$ & $\begin{array}{c}\text { Bobot x } \\
\text { Rating }\end{array}$ \\
\hline (A) Permintaan carica meningkat & $\mathbf{0 , 1 0 3}$ & 3,333 & $\mathbf{0 , 3 4 3}$ \\
(B) Tidak adanya barang substitusi & $\mathbf{0 , 1 1}$ & $\mathbf{3 , 4 6 7}$ & $\mathbf{0 , 3 8 1}$ \\
(C) Pangsa pasar luas & $\mathbf{0 , 0 9 3}$ & 3,133 & $\mathbf{0 , 2 9 1}$ \\
(D) Kemudahan mendirikan usaha & $\mathbf{0 , 0 9 3}$ & $\mathbf{2 , 4 6 7}$ & $\mathbf{0 , 2 2 9}$ \\
(E) Pelatihan dari dinas terkait & $\mathbf{0 , 1 0 3}$ & $\mathbf{2 , 9 3 3}$ & $\mathbf{0 , 3 0 2}$ \\
Ancaman & & & \\
(F) Harga bahan baku berfluktuatif & $\mathbf{0 , 0 8 8}$ & $\mathbf{1 , 5 3 3}$ & $\mathbf{0 , 1 3 5}$ \\
(G) Iklim usaha tidak stabil & $\mathbf{0 , 1 1 4}$ & $\mathbf{2 , 3 3 3}$ & $\mathbf{0 , 2 6 6}$ \\
(H) Kenaikan harga barang pembantu & $\mathbf{0 , 0 9 4}$ & $\mathbf{1 , 6 6 7}$ & $\mathbf{0 , 1 5 7}$ \\
(I) Bencana longsor di Dieng & $\mathbf{0 , 1 1 6}$ & $\mathbf{2 , 4}$ & $\mathbf{0 , 2 7 8}$ \\
(J) Hambatan pada musim kemarau & $\mathbf{0 , 0 8 7}$ & $\mathbf{1 , 2 6 7}$ & $\mathbf{0 , 1 1 0}$ \\
$\quad$ Total EFE & & & $\mathbf{2 , 4 9 4}$
\end{tabular}

Sumber: data primer, diolah, 2014.

Faktor-faktor eksternal yang berpengaruh terhadap industri carica ditunjukkan pada tabel diatas. Peluang utama bagi industri carica tersebut adalah tidak adanya barang substitusi carica di pasaran dengan bobot $\mathrm{x}$ rating terbesar yaitu o,381. Aancaman utama bagi industri carica yaitu hambatan pada musim kemarau dengan nilai bobot $\mathrm{x}$ rating terkecil yaitu o,110.

Strategi Pengembangan Industri Kecil Carica di Kabupaten Wonosobo Strategi SO (Strenght-Opportunity) antara lain Meningkatkan kualitas sumber daya manusia untuk meningkatkan kualitas produk carica; Memanfaatkan tenaga kerja dari daerah sekitar untuk peningkatan industri carica; Mengoptimalkan lokasi industri yang strategis, agar produsen menambah produksinya karena pasar produk carica sangat terbuka. Tenaga kerja menjadi penting mengingat salah satu pilar keberhasilan suatu usaha adalah pengelolaan dan perencanaan usaha yang matang (Karel, 2013).

Selanjutnya adalah Strategi WO meliputi, menyiapkan persediaan dalam bentuk stok barang untuk mengatasi masalah ketika kekurangan bahan baku; Mengoptimalkan produk khas daerah untuk memenuhi permintaan pasar; Mengoptimalkan pelatihan dari dinas untuk memenuhi dan menjaga kualitas produk carica.

Kemudian Strategi ST antara lain, Menjaga kualitas dan ciri khas produk agar 
dapat bersaing dengan industri carica yang lainnya; Mengantisipasi bencana longsor di dataran tinggi Dieng dapat dilakukan dengan penyuluhan kepada para masyarakat di daerah dataran tinggi Dieng; Melakukan inovasi produk carica yang bisa meningkatkan selera para konsumen.

Adapun langkah lain yaitu strategi WT yakni, Meningkatkan kemampuan manajerial pengusaha; Menaikkan harga jual produk carica untuk menutupi biaya produksi yang terus naik; Pada musim kemarau produksi carica bisa diganti dengan produk makanan olahan lainnya yang menjadi komoditas Kabupaten Wonosobo.

\section{KESIMPULAN}

Terdapat 15 unit usaha industri kecil carica, dimana jumlah unit terbanyak terdapat di Kecamatan Wonosobo yaitu ada 9 unit usaha. Industri kecil carica di Kabupaten Wonosobo mayoritas dikelola oleh responden pemilik industri kecil carica berumur produktif dengan tingkat pendidikan sebagian besar tamat SLTA.

Sebagian besar sumber modal industri kecil carica di Kabupaten Wonosobo berasal dari modal sendiri atau pribadi sebanyak 12 pengusaha. Kekuatan yang dimiliki industri kecil carica di Kabupaten Wonosobo adalah lokasi industri yang dekat dengan pasar.Kelemahan yang dimiliki adalah keterbatasan bahan baku yang tersedia.Peluang yang dimiliki industri kecil carica di Kabupaten Wonosobo adalah tidak adanya barang substitusi carica di pasaran.

Ancaman yang dimiliki industri kecil carica di Kabupaten Wonosobo adalah hambatan pada musim kemarau.Berdasarkan hasil penelitian strategi pengembangan yang dapat dilakukan oleh industri kecil carica di Kabupaten Wonosobo adalah strategi konsentrasi melalui integrasi horizontal. Strategi ini bertujuan memperluas usaha dengan cara meningkatkan jumlah produksi dan menambah jasa. Pada industri kecil carica di Kabupaten Wonosobo dapat meningkatkan kualitas produk dan memperluas pasar dengan cara promosi.

\section{DAFTAR PUSTAKA}

Adisasmita, H.R. (2005). Dasar-dasar Ekonomi Wilayah. Jakarta: Graha Ilmu.

Anoraga, Pandji., dan Djoko Sudantoko. (2002). Koperasi, Kewirausahaan, dan Usaha Kecil. Jakarta: PT Rineka Cipta.

Anwar, Moh Arsjad. (1986). Ekonomi Indonesia, Masalah dan Prospek 1986/1987. Jakarta:UI PRESS.

Arikunto, Suharsimi. (2006). Prosedur Penelitian. Jakarta: PT Asdi Mahasatya.

Azhary, Saleh Irsan. (1986). Industri Kecil Sebuah Tinjauan Dan Perbandingan. Jakarta: LP3ES.

BPS . (2014). Kabupaten Wonosobo Dalam Angka.Wonosobo:BPS Kabupaten Wonosobo.

Bustaman, Umi Salwa Ahmad. (2010). Growth Strategies among Small and Medium Enterprises - Case of Malay Entrepreneurs. Journal of Small Business Management, 36(4)

David, FR. (2008). Manajemen Strategis Konsep. Edisi Ketujuh Bahasa Indonesia. Jakarta: PT Indeks.

Karel, Skokan. et al. (2013). Strategic Planning and Business Performance of Micro, Small and Medium-Sized Enterprises. Journal of Competitiveness Vol. 5, Issue 4, pp. 57-72, December 2013

Kitching, John., and David Smallbone. (2012). Are freelancers a neglected form of small business?. Journal of Small Business and Enterprise Development, Vol. 19 Iss: 1 pp. 74 - 91

Kuncoro, Mudrajat. (200o). Usaha Kecil di Indonesia: Profil, Masalah dan Strategi Pemberdayaan. Website http://www.google.com. Diakses pada tanggal 20 Oktober 2014.

Lincolin, Arsyad. (1999). Pengantar Perencanaan dan Pembangunan Ekonomi Daerah. Yogyakarta: BPFE.

Purwaningdyah, Yunia Galih .et al. (2014). Efektivitas ekstrak biji pepaya (carica papaya 1.) Sebagai anti diare pada mencit yang diinduksi salmonella typhimurium. Jurnal Pangan dan Agroindustri Vol. 3 No 4 p.1283-1293, September 2014 
Rangkuti, Freddy. (2008). Analisis SWOT Teknik Membedah Kasus Bisnis. Jakarta: PT. Gramedia Pustaka Utama.

Sriyana, Jaka. (2010). Strategi Pengembangan Usaha Kecil dan Menengah (Ukm): Studi Kasus Di Kabupaten Bantul. Fakultas Ekonomi. UII. Yogyakarta.

Sukirno, Sadono. (2002). Pengantar Teori Mikro ekonomi. Jakarta: PT. Raja Grafindo Persada.
Suparmoko. M. (2002). Ekonomi Pembangunan. Yogyakarta: BPFE Yogyakarta.

Undang-Undang No. 5 Tahun 1984 tentang Perindustrian. Jakarta.

Undang-Undang No. 9 Tahun 1999 tentang Perindustrian. Jakarta.

Sagir, Suharsono. (2000). Membangun Manusia Karya. Jakarta: Pustaka Sinar Harapan. 